\title{
Gürültü Önleyici Akustik Malzemelerin Performans Düzeylerinin İncelenmesi
}

\author{
Hatice Mehtap Öz $z^{1}$ Ercan Köse ${ }^{2}$ \\ ${ }^{1}$ Tarsus Üniversitesi, Lisansüstü Eğitim Enstitüsü, İmalat Mühendisliği Anabilim Dalı, Tarsus, Mersin, Türkiye \\ 2 Tarsus Üniversitesi, Mühendislik Fakültesi, Elektrik-Elektronik Mühendisliği Bölümü, Tarsus, Mersin, Türkiye (ORCID: 0000-0001-9814-6339)
}

(İlk Geliş Tarihi 24 Ocak 2020 ve Kabul Tarihi 21 Şubat 2020)

(DOI: 10.31590/ejosat.679628)

\begin{abstract}
ATIF/REFERENCE: Öz，H. M. \& Köse, E. (2020). Gürültü Önleyici Akustik Malzemelerin Performans Düzeylerinin
\end{abstract} İncelenmesi. Avrupa Bilim ve Teknoloji Dergisi, (18), 1-10.

$\ddot{O} \mathbf{z}$

Doğal ve yapay birçok ortamda gürültü ile karşılaşmak kaçınılmazdır. İş Sağlığı ve Güvenliği Yönetlmeliğinde de belirtildiği gibi 85dB (desibel) üzeri ses ve gürülttüyle karşılaşmak insan sağlığı için kalıcı sorunlara yol açabilir. Söz konusu bu zararlardan insanları korumak için çeşitli çözüm önerileri geliştirilmiştir. Kulaklık kullanılması, ses ve gürültünün kaynağında uzaklaştırılması, ses ve gürültünün bastırılması ve yalıtılması önemli başarımlar sağlamıştır. Gürültüyü bastırmak için deneysel olarak da kanıtlanmış olan, akustik köpük veya sünger şeklinde malzemeler, doğal lifler (koyun lifleri, hindistan cevizi, çay lifi ve kenevir lifleri vb. doğal ve sentetik liflerden elde edilen mikrolifler ve cam yünü şeklindeki malzemelerin kullanılması gerekir. Akustik özelliklerinin iyi olması açısından; süngerlerin, doğal liflerden üretilen dokuma ve örme kumaşların, mikroliflerden elde edilen kumaşların, geri dönüştürülmüş dokusuz yüzeylerden elde edilmiş kumaşların iyi bir performans gösterdiği ortaya çıkmıştır. Ayrıca, yeni bir çalışma olarak gürültünün bastırılması yani gücünün azaltılması için sentetik liflerden, özellikle de akrilik liflerden elde edilebilecek dokuma, örme, dokusuz yüzey şeklindeki kumaşların veya süngerlerin deneysel olarak incelenmesi ve sonuçlarının analiz edilmesi önemli sonuçlar sağlayabilir. Çünkü akrilik lifleri, yapısı itibariyle diğer liflere göre daha gözenekli yapıya sahiptir. Ses absorbe etmede ise gözenekli yapılar önemli bir noktaya sahip olduğundan dolayı deneysel çalışmalarda malzeme olarak seçilmesi ile çalışmanın hedefi açısından önemli aşamalar kaydedilebilir.

Anahtar Kelimeler: Akustik Malzeme, Gürültü, Lif, Kumaş, Dokuma, Örme.

\section{Investigation Of The Performance Levels Of The Noise Preventive Acoustic Materials}

\begin{abstract}
It is inevitable to encounter noise in many natural and artificial environments. As stated in the Occupational Health and Safety Regulation, encountering noise and noise above $85 \mathrm{~dB}$ (decibel) can cause permanent problems for human health. Various solutions have been developed to protect people from these damages. The use of headphones, moving away from the source of sound and noise, suppression and isolation of sound and noise have made important achievements. The experimentally proven to suppress noise, materials in the form of acoustic foam or sponge, natural fibers (sheep fibers, coconut, tea fiber and hemp fibers, etc.), microfibres obtained from natural and synthetic fibers and glass wool materials should be used. In terms of good acoustic properties; It has been revealed that sponges, woven and knitted fabrics made from natural fibers, fabrics made from microfibers, fabrics made from recycled non-woven surfaces perform well. In addition, as a new study, experimental investigation and analysis of woven, knitted, non-woven surface fabrics
\end{abstract}

\footnotetext{
* Sorumlu Yazar: Tarsus Üniversitesi, Lisanüstü Eğitim Enstitüsü, İmalat Mühendisliği Anabilim Dalı, Mersin, Türkiye, hmehtap@yahoo.com
} 
or sponges that can be obtained from synthetic fibers, especially acrylic fibers, to suppress noise, to reduce its power, can provide important results. Since porous structures have an important point in sound absorption, important steps can be recorded for the target of the study by selecting them as materials in experimental studies.

Keywords: Acoustic Material, Noise, Fiber, Fabric, Weaving, Knitting.

\section{Giriş}

Ses, havadaki basınç değişimlerinin bir sonucu olarak tanımlanır. Havadaki bu basınç değişimleri, kulak zarını harekete geçirerek ses üretilmesini sağlar. İnsan kulağı çok geniş bir alanda bile ses basıncını ayırt edebilecek özelliğe sahiptir [1]. Sesin yüksekliğini belirleyen faktör ise frekansıdır. Sesin frekansı ve oluşturduğu basınç, ses yüksekliğini belirlemede önemli faktörlerdir. Sağlıklı bir insanın kulağının işitebileceği frekans aralığ $20-20000 \mathrm{~Hz}$ (Hertz) olarak tespit edilmiştir. Buna göre de 20 Hz' in altındaki sesler, ses berisi (infra sound), $20000 \mathrm{~Hz}$ ' in üstündeki sesler ise ses ötesi (ultra sound) olarak tanımlanmıştır. Bir konuşmanın anlaşılabilir olması için 200-5000 Hz aralığında olması beklenir. Müzik açısından bakıldığında ise 30 ile $10000 \mathrm{~Hz}$ aralığındadır. Kulağın en hassas olduğu frekans aralığı ise 3000 ile $4000 \mathrm{~Hz}$ dir. Frekans kadar sesin karakteristiğini belirlemek için kullanılan önemli bir başka büyüklük ise güçtür [1]. Sesin gücünü belirlemede ise ölçek olarak ses basınç seviyesi kullanılmakta olup desibel ile ifade edilmektedir. Bir kaynaktan çıkan ses, duyulabilir sesin bir katı olduğundan bu ses, desibel değerini ifade etmektedir [1]. Desibel değerlerinin seviyesi yükseldikçe insanlar için zararlı olabilmektedir. Bu durum gürültüyü ortaya çıkarmaktadır. Zararlardan insanları korumak için gürültü kontrolü yapılması gerekir. Gürültü kontrolü temel olarak; gürültüyü oluşum kaynağında azaltmak, gürültüyü yayılma alanında azaltmak ve gürültünün algılandığı yerde yapılacak çalışma ve önlemler şeklinde üç farklı şekilde sağlanabilmektedir. Yoğun ses tempolarının meydana geldiğini alanlarda sesin gücünü azaltmak için ses izolasyon uygulamaları yapılmaktadır. İnsan hayatı boyunca birçok alanda ses problemleriyle karşılaşabilmektedir. Bu anlamda; karayolu, havayolu gibi ulaştırma gürültüleri, endüstriyel makinelerden ve makine dairelerinden kaynaklanan gürültüler, titreşimler, havalandırma kanallarının gürültüsü, inşaat gürültüleri, spor sahaları ve eğlence merkezlerinin gürültüsü, yüksek sesli reklam ve müzik yayınlarının oluşturduğu gürültüler, doğal iklim olayları ve yağmur gürültüsü gibi örnekler verilebilir [3].

Günlük hayatımızda bazı sesler bizi rahatlatan etkiye sahipken bazı sesler rahatsızlık yaratabilmektedir. Bunun nedeni, desibel değerlerinin farklı olması ve seviyenin yükseldikçe zarar verici olmasıdır [4]. Söz konusu gürültüleri azaltmak için çeşitli akustik malzemeler tercih edilmektedir. Bu akustik malzemeler, değişik formlara sahip sünger, kauçuk, melamin vb. yapıda olabilmektedir. Bu alanlara yapılan ses izolasyonu için kullanılan akustik malzemeler ile daha kaliteli bir ortam sağlanabilmektedir [3]. Ayrıca, gürültüyü azaltmak ve önlemek amacıyla birçok farklı yöntemler kullanılmaktadır. Bu yöntemler, periyodik olarak makine bakımlarının yapılması, gerektiğinde susturucu parçaların tercih edilmesi, gürültüye neden olan kaynağın, sesi absorbe edici ve ses yalıtımını sağlayabilecek yutucu malzemeler ile kaplama yapılması, titreşimin meydana geldiği noktalarda titreşimin sönümlenmesini sağlamak amacıyla kauçuk gibi bir malzemeyle kaplama yapılması, gürültü kaynağını kapalı hale getirerek malzeme ve tasarım değişiklerin yapılması şeklinde verilebilir [3].

Örneğin; CST ve HFSS programları kullanılarak, gürültü önleyici malzemelerin geliştirilmesi üzerine birçok akademik çalışma bulunmaktadır. Üstün ve ark. [5], optimal tasarımlı çok katmanlı RAM ile kaplanmış bir aracın (MRAM), sinyalin soğurularak radar sistemlerinden gizlenebilmesi ile ilgili çalışma yapmışlardır. Bu sistemde, katmanların çeşitli varyasyonlarıyla MRAM'ın dizaynındaki farklılıklar, doğal ilham kaynağından biri olan yapay arı kolonisinden esinlenen (ABC) algoritmasının kullanılmasıyla optimal hale getirilmiştir. MRAM'lar normalde 2-8 GHz ve 1-20 GHz frekans aralığında çalıştığından dolayı elektriksel değişkenler ve her bir katmanın kalınlığı, toplam sınırlı bir kalınlık için yansıtmayı minimize etmek için optimize edilmiştir. Ayrıca MRAM'lar aracılığıyla karşılaştırma yapılarak tasarlanmış farklı algoritmalardan biri için öneride bulunulmuştur. Bu alanla ilgili bir başka çalışmada; Malawade ve ark. [6], doğal liflerin gözenekli yapılarının akustik özelliklerini araştırmışlardır. Gözenekli köpük ve lifli yapıya sahip olan gözenekli malzemelerin yüksek oranda ses emme kabiliyetine sahip olduğunu, bu nedenle de gürültü kontrolünde önemli role sahip olduğunu belirtmişlerdir. Özellikle de köpüklerin, ses enerjisini hapsedebilecek iç boşluklara sahip olması nedeniyle de akustik emici ortamlar olarak rol oynadığını, cam yünü, poliüretan köpük, asbest vb. malzemelerin pahalı ve yanıcı olması nedeniyle tercih edilmediğini belirtmişlerdir. Bu nedenle de doğal lifler üzerine deneysel çalışmalar yapmışlardır. Bu çalışmalarda, ahşap tozu, pirinç kabuğu, pirinç samanı ve küspeden hazırlanan örnekler verilmektedir. Ayrıca pirinç kabuğu, pirinç samanı ve odun tozu kombinasyonları ile hazırlanan numunelerde akustik özellikte olumlu yönde gelişmeler gözlemişlerdir. Bu liflerin yanı sıra hindistan cevizi, çay lifi ve kenevir liflerini de kullanmışlardır. Çay lifi için 500 ile $3200 \mathrm{~Hz}$ ve 500 ile $2400 \mathrm{~Hz}$ frekans aralıklarında 20 ve $30 \mathrm{~mm}$ örnek kalınlıklarını incelemişlerdir. Çay lifinin ses azalımında ve hindistan cevizi lifinin ise delikli yüzeyler yardımıyla iyi bir alternatif olabileceğini belirtmişlerdir. Ahşap tozu, pirinç kabuğu, pirinç samanı ve küspelerinden elde edilen artık liflerinden hazırlanan numunelerle ve bunun yanısıra dört malzemeye de aynı basıncı uygulayarak güneşte kurutma süresi sabit olacak şekilde deneyler yapmışlardır. Ölçüm esnasında ise ortam seslerinden uzak kalmak için deney düzeneğinde kullanılan kutunun iç yüzeylerinde köpük kullanarak ses yalıtımını sağlamışlardır. Sonuç olarak; pirinç samanı liflerinden alınan örneklerde, $125 \mathrm{~Hz}$ ve $1500 \mathrm{~Hz}$ frekans aralığı için odun tozu ve pirinç samanı kombine edilerek yapılan numunelerde ses emme yeteneğinin iyi olduğu, maksimum ses emme katsayısının ise pirinç samanı ve ahşap tozu bileşiminden hazırlanan numunelerde ise maksimum düzeyde olduğunu tespit etmişlerdir. Odun tozu ve pirinç samanı kompozitinden hazırlanan numunelerle yapılan testler sırasıyla $22 \mathrm{~dB}$ ve $20 \mathrm{~dB}$ maksimum ses kaybını göstermektedir. Önemli bir diğer çalışmada; Zent ve ark. [7], sesin iletimi ve gürültünün azaltılması konusunda, farklı gözeneklere ve kalınlıklara sahip (pamuk lifi karışımları ve mikrofiberler gibi) malzemeler geliştirmişlerdir. Numunelerin belirli kalınlıkta ve hava akışına karşı gösterilen direnç açısından iyi düzeyde olduğunu tespit etmişlerdir. Yaptıkları çalışmada, emilimin etkinliğinin doğrudan malzemenin kalınlığı ile alakalı olduğunu, ses emicilerin yüksek frekanslarda daha etkili olduğunu belirtmişlerdir. On üretici, kalınlıkları 6,4 mm- 36,5 mm aralığında olan 128 adet numune ile yaptığı deneyleri değerlendirmişlerdir. Bu malzemeler pamuk, polyester ve polipropilen liflerden oluşan 
dokusuz yüzeylerdir. Mikroliflerin kullanılması ise hava akış direncinin yüksek olması yani sesin yalıtılması konsunda da önemli bir noktaya sahip olduğunu belirtmişlerdir.

Söz konusu konuya bir alternatif yaklaşım getiren Kalebek [8], geri dönüştürülmüş dokusuz yüzey malzemeler kullanmıştır. Dokusuz yüzey kullanımının, maliyet ve akustik özellik açısından avantajlı olduğunu ortaya koymuştur. Birim alana düşen kalınlık ve yoğunluk, kütle, hava geçirgenliği, gerilme mukavemeti gibi fiziksel özelliklerin, akustik özelliği ne yönde etkilediği test edilmeye çalışılmışır. Testten elde edilen veriler, Design Expert yazılımı ile istatiksel açıdan değerlendirildiğinde, birim alandaki kütle artışının hava geçirgenliğini azalttığını da göstermiştir. Deney, $20^{\circ} \mathrm{C}$ ve bağıl 48 saat boyunca $\% 63$ nem koşullarında gerçekleştirilmiştir. Kalınlık, yoğunluk, hava geçirgenliği ve gözenekli yapının, ses yalıtımında önemli olduğu kanısına varılmıştır. Otomotiv sektöründe geri dönüştürülmüş malzemelerle elde edilen dokusuz yüzeylerin, akustik özelliklerinin iyi olmasının yanında maliyet açısından da avantaj sağladığı ortaya konulmuştur. Diğer bir çalışmada Liao ve ark. [9], düşük yakıtlı hibrit elektrikli araçların (HEV'in), hibrit iletiminin gürültüyü ve titreşimi azaltmada ne derecede etkili olabileceğini araştırmışlardır. Araçlarda titreşime yol açan, planet dişliler, rulmanlar, miller gibi parçaların gürültüye neden olduğunu belirlemişler ve oluşan bu gürültüyü azaltmaya odaklanmışlardır. Hibrit araçlarda titreşim ve gürülttüyü önlemek amacıyla, bakır, demir ve çelik gibi metal malzemeler kullanılmıştır. Ayrıca daha hafif olan alaşımlı çelik, alüminyum-magnezyum alaşımı gibi malzemeler tercih edilmiştir. Gürültü ve titreşim testlerini yapabilmek için hibrit iletim hızı ile direnç gibi koşullar dikkate alınmıştır. Test sistemi ile gürültünün kaynağı tespit edilmeye çalışılarak titreşim ve gürültü azaltılmaya çalışılmıştır. Sonuç olarak; sesin emilimi için kullanılacak malzemelerle iletimin etkili bir şekilde azaltılabilmesi için gerekli tasarımların yapılmasının ekonomik açıdan da büyük öneme sahip olduğunu tespit etmişlerdir.

Akustik kumaşlarla ilgili olarak çalışma yapan Öztürk ve ark. [10], örme kumaşları tercih etmişlerdir. Örme kumaşlar, dokuma kumaşlara göre daha gözenekli bir yapıya sahiptir. Bu gözenekli yapıya sahip olan kumaşın kalınlığını artırmak için ön ve arka yüzeylerinde elastomer iplik, ön ve arka yüzey arasında polyester iplik ve arka yüzeyinde ise boşlukların azalması için elastanlı iplikler kullanmışlardır. Bu durumda, önde ve arkada yer alan kumaşlar arasındaki hava boşluğu ve önde bulunan kumaşın kalınlığının arttığını ve kumaştaki gözenekler küçüldüğü için kumaşın ses (gürültü) yutma performansının arttığını görmüşlerdir. Dolayısıyla, kumaşların ses yutum katsayısı arttıkça hava geçirgenliği direncinin arttığını ortaya çıkarmışlardır. Dahil ve ark.[11], gözenekli olan ve gözenekli olmayan malzemelerle deneysel çalışmalar yaparak titreşim büyüklüğünü tespit etmeye çalışmışlardır. Metalik köpük kullanarak yaptıkları çalışmada kapalı ve açık hücreli kullanımları söz konusudur. Sönümleme katsayısı gözeneğin yapısına bağlı olarak belirlenmektedir. Yaptıkları çalışmada, gözeneklerin sayısının artmasıyla sönümlemenin arttığını ve gözenekli magnezyumun gözenekli olmayan magnezyumdan daha iyi düzeyde olduğunu belirlemişlerdir. Metalik malzemelerin hücresel yapılarından dolayı mekanik sönümlemenin yapısal faktörlere ve test koşullarına bağlı olduğunu da tespit etmişlerdir. Kaya ve ark. [12], kenaf, ahşap, kenevir, hindistan cevizi, hurma ağacı, çay yaprağı, lif kabağı ve koyun yünü gibi doğal liflerin ses yutma kapasitelerini araştırmışlardır. Bu liflerle farklı kalınlıklarda numuneler üretip hangi frekans aralıklarında ses emme kabiliyetinin daha iyi olduğunu belirlemeye çalışmışlardır. Sonuç olarak da; doğal liflerden gözenekli yapıya sahip olanların ses yalıtımı konusunda iyi performans gösterdiğini, iyi performans gösterebilmesinde ise homojen dağılım miktarı, gözenekli yapı ve yoğunluğu ile kalınlığın önemli parametreler olduğunu belirtmişlerdir. Liflerin kalınlığındaki artma, düşük frekans aralığında bile ses yalıtım değerini artırabilmektedir. Akustik açıdan 6 oktav olup frekanslar; 125, 250,500, 1000, 2000, $4000 \mathrm{~Hz}$ olarak belirlenmiştir. Ölçümlerin değerlendirmesini bu oktavlarda yapmışlardır. Bahsedilen frekans aralıklarında ise beklenen değerlerin elde edilebileceğini tespit etmişlerdir. Özellikle de $1000 \mathrm{~Hz}$ ve üzerindeki frekanslarda, darbe titreşimlerini engelleyebilecek şekilde kalınlığın da artmasıyla akustik özelliğin arttığını gözlemlemişlerdir. Ayrıca doğal liflerin sağlık, çevre ve ekonomik açıdan da önemli faktörler olduğunu belirlemişlerdir.

$\mathrm{Bu}$ çalışmada ise; gürültü ile ilgili temel kavramlar verilerek, gürültünün önlenmesi için kullanılan akustik malzemeler incelenip, önemli ve kritik noktalar değerlendirilmiştir.

\section{Gürültü, Frekans ve Güç}

Ses, nesnel bir kavram olup ölçülebilir bir değere sahiptir, fakat öznel bir kavram olarak nitelendirilen gürültü, istenmeyen ses olarak tanımlanmaktadır. Ayrıca gürültü şiddetine göre rahatsız edici olabilmektedir. Çok yüksek olan sesler psikolojik rahatsızlıklara bile yol açabilmektedir. Bu yüzden, gürültüyü ölçmek amacıyla ses seviye ölçer aleti kullanılmaktadır [1]. Sesin rahatsız edici boyutta olup olmaması ses kaynağına bağlı olarak değişkenlik göstermektedir. Bu açıdan bakıldığında, gürültü kaynağına göre ses seviyeleri aşağıdaki Tablo 1'de verilmiştir [4].

Tablo 1 de görüleceği üzere, 70 dB'den sonraki ses seviyeleri, sağlık açısından risklidir. Bu nedenle de gürültü kaynağına göre önlemler alınması gereken durumlar ortaya çıkmaktadır. Örneğin, fabrika ortamlarında bazı makinalardan çıkan yüksek sesin vereceği zararı engelleyebilmek için kulak tıkaçları kullanılmaktadır.

Ses, bir enerji türü olup dalgalar halinde yayılım göstermektedir. Sesin oluşabilmesi için gerekli bir parametre olan titreşimin yayılabilmesi için hava ve su gibi akustik ortamlara ihtiyaç bulunmaktadır. Sesin dalgalar halinde yayılması ise bu akustik ortamda basınç değişikliğine neden olmaktadır. Örnek verilecek olursa, havada yayılan sesin, atmosferik basınçta oluşturduğu değişim miktarı ses basınc olarak tanımlanmaktadır [1]. 
Tablo 1. Gürültü Kaynă̆ına Göre Ses Seviyeleri [4]

\begin{tabular}{|c|c|c|}
\hline Gürülttünün Kaynağı & dB (A) & \\
\hline Sessizlik & 0 & \multirow{7}{*}{ Etki yok } \\
\hline Nefes alma & 10 & \\
\hline Fisıldama, düsen yapraklar & 20 & \\
\hline Sakin alanlar & 30 & \\
\hline Kütüphane & 40 & \\
\hline Düşük seviyede konuşma, rüzgâr türbini & 50 & \\
\hline Lokanta gürültüsü, uğultu & 60 & \\
\hline TV sesi, Bilgisayar & 70 & Bazıları için rahatsızlık verebilir \\
\hline Fabrika & 80 & Uzun sürede işitme bozuklukları \\
\hline $\begin{array}{l}\text { Çim biçme makinasl, araba içinde } \\
\text { maruz kalınan ses }\end{array}$ & 90 & Uzun sürede işitme bozuklukları \\
\hline Dıştan takılmış motor & 100 & Uzun sürede ileri seviyede işitme bozuklukları \\
\hline Rock konseri, sanayi gürültüsü & 110 & Hemen zarar verebilir veya uzun sürede işitme bozuklukları \\
\hline Gök gürültüsü, havalı matkap & 120 & Genellikle hemen zarar verir. \\
\hline Jet uçăgl & $130-150$ & Ani işitme kaybı veya kulak zarının yırtılması \\
\hline
\end{tabular}

Sesin desibel değeri, duyulan sesin duyulabilir en düşük sesten kaç kat fazla olduğunu göstermektedir ve Eşitlik 1'deki gibi hesaplanmaktadır [1].

$\mathrm{I}=$ Duyulan ses ve $\mathrm{I}_{0}=$ Duyulabilir en düşük ses olmak üzere;

$$
I(d B)=10 * \log _{10}\left(\frac{I}{I_{0}}\right)
$$

eşitliğiyle hesaplanmaktadır. Bir kaynaktan çıkan ses, duyulabilir sesin bir katı olduğundan bu ses desibel değerini ifade etmektedir. Eşitlik 2 ve 3'de örnek verecek olursak;

$$
\begin{aligned}
& I=1000000000 * I_{0} \\
& I(d B)=10 * \log _{10}\left(\frac{1000000000 * I_{0}}{I_{0}}\right) \\
& I(d B)=10 * 9=90 d B
\end{aligned}
$$

şeklinde bulunmaktadır [2]. Sesin gücü, bir ses kaynağından yayılan ses enerjisinin gücü, ses basıncı ise sesi oluşturan hava basıncının değiş̧me miktarı olarak tanımlanmaktadır. Ses gücünün birimi, birim zamanda yayılan ses enerjisi olmak üzere birimi Watt olarak ifade edilmektedir. $\mathrm{P}$, watt cinsinden ses gücü, $\mathrm{I}, \mathrm{W} / \mathrm{m}^{2}$ cinsinden ses şiddeti ve $\mathrm{dS}, \mathrm{m}^{2}$ cinsinden birim yüzey alanı olmak üzere, ses gücü Eşitlik 4'deki gibi hesaplanmaktadır [3].

$$
P=\int_{S} I d S
$$

Sesin gücü, makinaların çıkardıkları gürültüye göre sıralanmasında, ses şiddeti ise gürültü kaynaklarının tespitinde kullanılmaktadır. Gürültü kaynaklarının tahribat ve kötü etkileri için izlenmesi gereken en önemli parametre ise ses basıncıdır [13].

Ses basınç birimi Pascal olup N/m2 şeklinde gösterilmektedir. İnsan kulağının işitebileceği alt sınır, 2x10-5 Pa olup üst sınır 20 Pa civarındadır. Ses basınç düzeyi logaritmik bir büyüklük olduğundan aşağıdaki Eşitlik 5'deki gibi, referans ses basıncı ise Eşitlik 6'daki gibi hesaplanmaktadır [1].

$$
S P L=L_{P}=10 \log \left(\frac{p}{p_{\text {ref }}}\right)^{2}=20 \log \left(\frac{p}{p_{\text {ref }}}\right)(d B)
$$




$$
P_{r e f}=2 \times 10^{-5} P a
$$

Basıncın zamana bağlı değişimi Şekil 1'de ve ses basınç düzeyi-frekans grafiği ise Şekil 2'de verilmiştir [13]. Bu grafiğe göre, 30$65 \mathrm{~dB}$ aralığı, I. dereceden gürültüler olarak, 65-90 dB aralığ1, II. dereceden gürültüler, 90-120 dB aralığ1, III. dereceden gürültüler,

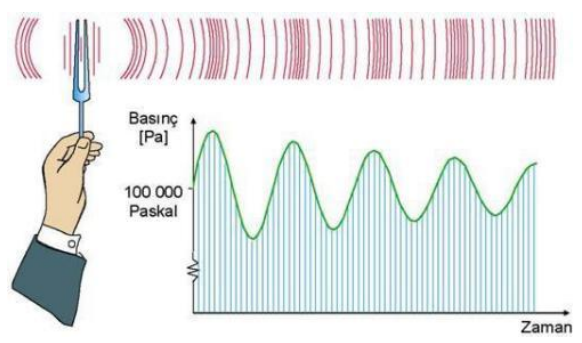

120-140 dB aralığg IV. dereceden gürültüler, 140 dB'in üzerindekiler ise V. dereceden gürültüler olarak sınıflandırılmaktadır. III. derece gürültülerden itibaren, sağlık açısından riskli bir ortam ortaya çıkmaktadır [13].

Şekil 1. Ses Basıncının Zamana Bağlı Değişimi [13]

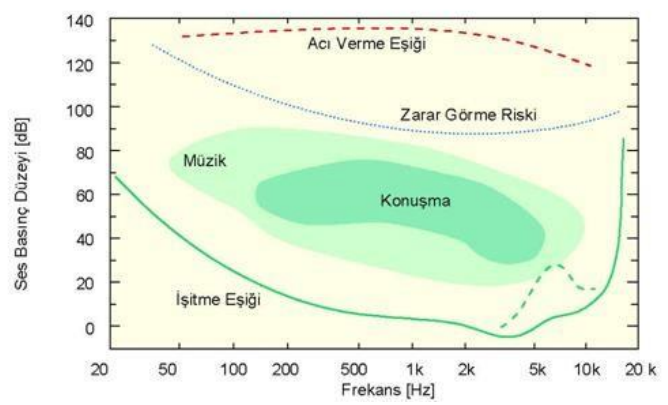

Şekil 2. Ses Basınç Düzeyi- Frekans Grafiği [13]

Saniyede oluşan ses miktarı, sesin frekansı olmak üzere birimi Hz olarak bilinmektedir. Bir hoparlörün, bir tüpün ucuna monte edilmesi durumunda, yayılma hızı $344 \mathrm{~m} / \mathrm{s}$ olan ses dalgaları ürettiği bilinmektedir. Üretilen bu ses, arı haldeki bir sinüs dalgası olması durumunda, birbirlerinden bir dalga boyu uzaklıkla belirlenmiş, maksimum ve minimum basınçlar meydana getirmektedir. Dalga boyu, frekans ve ses hızıyla ilgili bir kavramdır. Sesin dalga boyunun gösterimi Şekil 3'de verilmiştir [13]. Sesin frekansı ile oluşturduğu basınç, sesin yüksekliğini belirlemektedir [3].

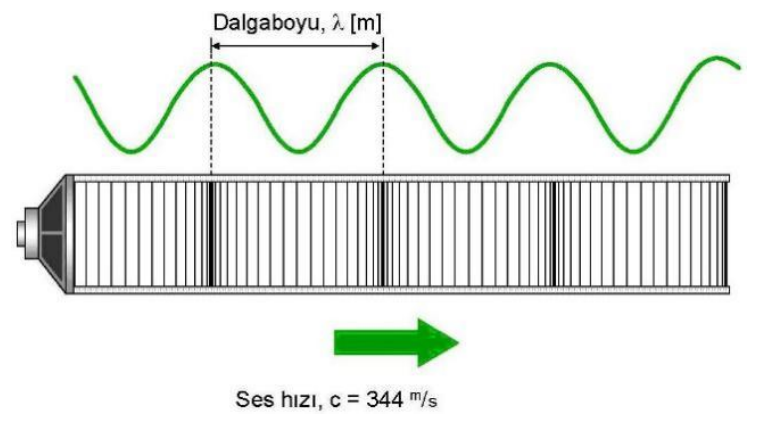

Şekil 3. Sesin Dalga Boyu [13]

Ses dalgaları, yayıldığı ortamın özellliklerine bağlı olarak değişimlere uğramaktadır. Örneğin; ses dalgaları, dalga boyundan büyük olan engellere çarpması durumuda yansıma ortaya çıkmaktadır. Bu engellerin dalga boyundan küçük ve düz olmayan yüzey (pürüzlü yüzey) olması durumunda, ses dalgaları yayılmayarak her yöne dağılım gösterebilmektedir. Bu durum, saçılma olarak da nitelendirilmektedir. Yansıma ve saçılma Şekil 4'de gösterilmektedir [14]. 


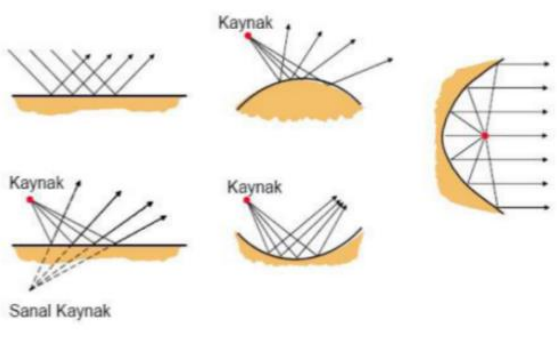

Yansima

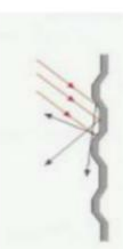

Saçılma

Şekil 4. Yansıma ve Saçılma [14]

Yutulma ise; sesin bir malzemeden geçmesi veya bir yüzeye çarpması esnasında, ses enerjisinin şekil değiştirmesidir. Bu anda ortaya çıkan enerji, çoğunlukla ısı enerjisi olarak bilinmektedir. Şekil 5'de A gelen ses, B yansıyan ses, C yüzey tarafından yutulan ses, D gözenekli yüzey ve E ise duvar olmak üzere yutulma olarak verilmiştir [14].
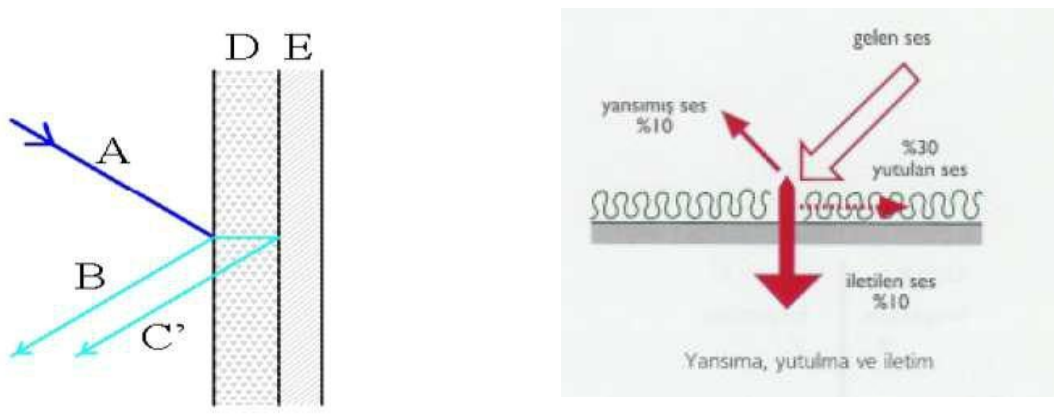

Şekil 5. Yutulmanın Şekli [14]

\section{Akustik Malzemeler}

Herhangi bir yüzeye gelen sesin bir miktarı yansımaktadır. Yansıyan bu sesin havada yol almasıyla ses çamurlaşması adı verilen durumun ortaya çıkması, sesin anlaşılması ve algılanmasını önlemektedirler. Bu yüzden, herhangi bir gürültü kaynağından gelen sesin (özellikle de 80- 85dB üzerinde), büyük oranda yansımasından önce absorbe edilmesinde, akustik kumaşla yapılan kaplamalar önemli bir yere sahiptir [15].

Doğal hammaddeye sahip olan akustik kumaşlar, darbelere karşı mukavemet göstermektedir. Bu nedenle de kapalı ortamlar, konferans salonları, hastaneler, kapalı spor salonları ve gösteri merkezleri gibi gürültünün yoğun olduğu alanlarda kullanılan malzemelerdir. Ayrıca araçlarda, yolcunun bulunduğu bölümde, motordan fazla miktarda gelen ve rahatsız edici boyutta olabilen gürültüyü de minimum düzeye indirmek hedeflenmektedir. Bu nedenle de gürültü kaynaklarını azaltmak amacıyla da zemin kaplamaları, kapı panelleri, tavan döşemeleri ve gövde bölümlerine entegre edilmiş ses absorbe edici malzemeler kullanılmaktadır. Bu malzemeler, hem kumaş hem de sünger olarak üretilebilmektedir [16].

Kumaş yapısında olanlar; ahşap panel arkasına kullanılan keçe kumaşlar ve panel ön yüzeyine kaplanan kumaşlar olarak iki sınıfa ayrılmaktadır. Panel ön yüzeyine kaplanan kumaşlar, aşınmaya, solmaya ve yanmaya karşı da mukavemet gösterebilmektedir. Şekil 6’da, ahşap panel arkasına kaplanan kumaş olarak kullanımı verilmiştir [16].

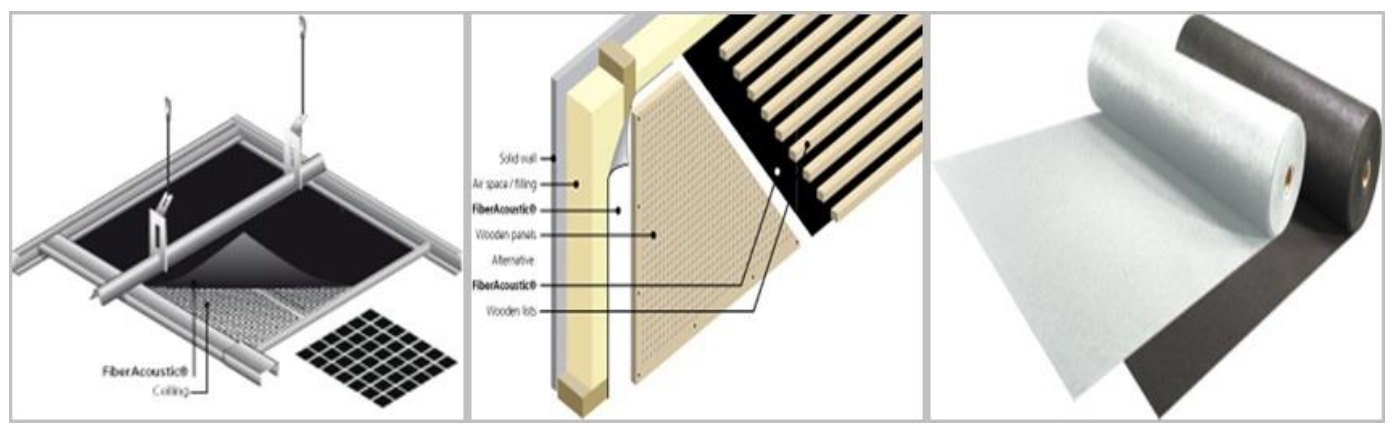

Şekil 6. Ahşap Panel Arkasına Kullanılan Kumaşlar [16]

Ses yalıtımında kullanılan bir malzeme olan süngerler, ses emiliminin iyi düzeyde olması nedeni ile önemlidir. Bundan dolayı süngerler, piramit, yumurta, labirent, special bondex, bariyerli yalıtım, düz ve melamin köpüğü şeklinde üretilebilmektedir. Ayrıca bahsedilen şekillerde üretilen süngerlere yanmazlık özelliği de kazandırılabilmektedir. Bunun yanısıra, açık gözenekli ve poliüretan 
yapıda olan süngerler, yalıtım ve akustik özellik açısından tercih edilmektedir [17]. Bu süngerler epdm kauçuk adı verilen ses bariyerleri ile birlikte kullanılabildiğinden ses geçiş kaybını sağlamada önemli bir yere sahiptir [3].

Akustik süngerin düz şekilde olanı, yüksek frekanslı sesleri \%80 oranında azaltırken düşük frekanslı seslerin tamamen ortadan kaldırılmasında büyük etkiye sahiptir. Düz akustik sünger Şekil 7'de verilmiştir [17].

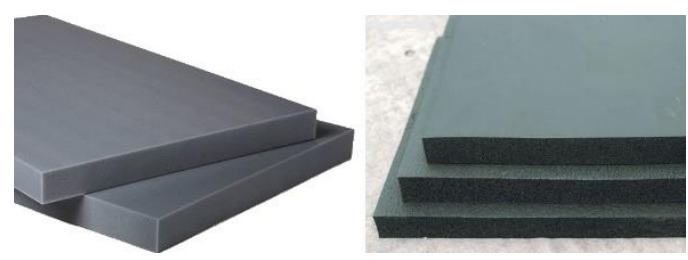

Şekil 7. Düz Akustik Sünger [17]

Piramit süngerler, $100 \mathrm{~cm}$ x $100 \mathrm{~cm}$ ebatlarında olmak üzere, 40,50 ve $70 \mathrm{~mm}$ kalıllıklarında üretimleri mevcuttur. $-5^{\circ} \mathrm{C}^{\prime}$ den +100 ${ }^{\circ} \mathrm{C}$ 'ye dayanabilme özelliklerine sahip olmasının yanısıra ses yutma kapasitesi ise $0,30-1,12$ aralığında dır. Piramit şeklinde olan sünger Şekil 8'deki gibidir [3].

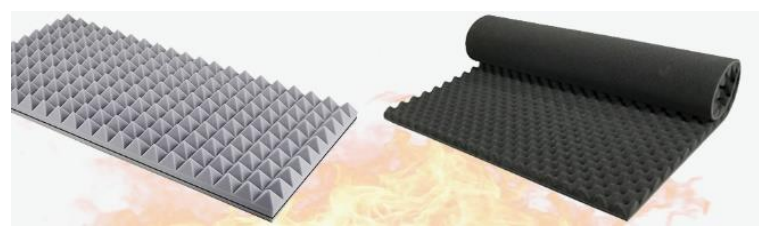

Şekil 8. Piramit Şeklinde Akustik Sünger [3]

Akustik süngerlerin bir diğer şekilde üretileni de yumurta şeklinde olanıdır. Ses absorbe etme açısından iyi derecede olduğu bilinmektedir ve yanmaz özellik de kazandırılabilmektedir. Bu süngerlerin üretilmesinde poliüretan malzeme kullanılmaktadır. $100 \mathrm{~cm}$ x $100 \mathrm{~cm}, 30 \mathrm{~mm}, 40 \mathrm{~mm}$ ve $50 \mathrm{~mm}$ ebatlarında üretimleri mevcut olup $-5^{\circ} \mathrm{C}$ 'den $+100{ }^{\circ} \mathrm{C}$ sıcaklığına dayanım gösterebilen ve ses yutma katsayısı 0,30-1,12 aralı̆̆ında olabilen malzemelerdir. Şekli 9'da, yumurta şeklinde olan süngerler gösterilmiştir [3].

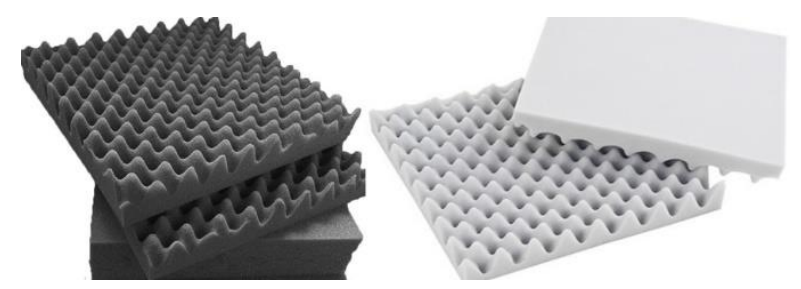

Şekil 9. Yumurta Şeklindeki Akustik Sünger [3]

Akustik süngerlerin özel yapıda olanları da mevcuttur. Bu şekilde olanların yoğunlukları $70 \mathrm{~kg} / \mathrm{m} 3$, kalınlıkları ise $40 \mathrm{~mm}$ ile 50 mm olup orta ve yüksek frekans bantları ve düşük frekans bantlarında etkili olabilmektedir. Daha çok sinema salonu, ses kayıt odaları, enstrüman çalınan kapalı alanlar vs gibi yerlerde kullanılmaktadır. Epdm ses bariyerleri, bondex süngerler ve düz akustik süngerler ile de kullanılabilmektedir. Nemden etkilenmeyen, küf tutmayan, esnek olduğu için de kolay şekillenebilir özelliğe sahiptir. Şekil 10’da special sünger görülmektedir [3].
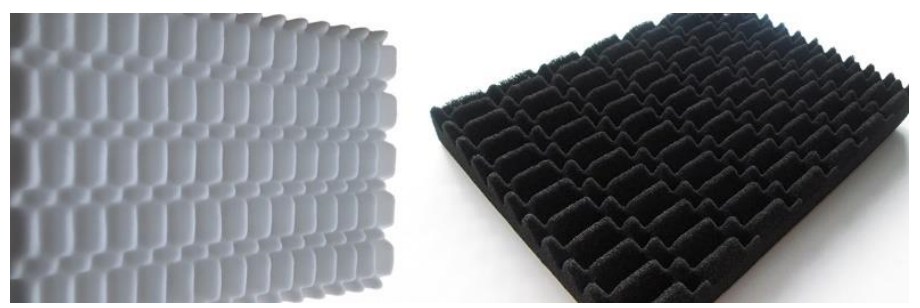

Şekil 10. Special Süngerler [3] 
Farklı yüzeye sahip fakat özellikleri diğerleri ile aynı olan akustik süngerlerden biri de labirent süngerdir. Ses miktarının yüksek olduğu alanlarda da etkili sonuçlar elde edilebilmektedir. Bu süngerler, 50 DNS, 70 DNS, 90 DNS yoğunluklarında, $30 \mathrm{~mm}, 40 \mathrm{~mm}$ ve $50 \mathrm{~mm}$ kalınlıklarında üretilebilmektedir. $-5^{\circ} \mathrm{C}$ ve $+100^{\circ} \mathrm{C}$ sıcaklıklara kadar dayanımları mevcuttur. Ses yutma kapasitesi ise 0,30 1,12 'dir. Şekil 11'de labirent sünger görülmektedir [3].

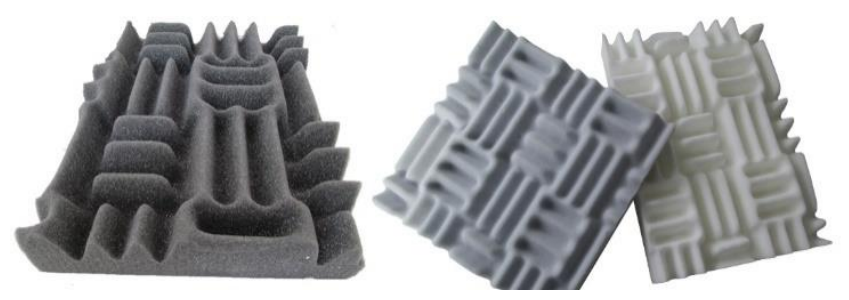

Şekil 11. Labirent Süngerler [3]

Ses yalıtımında, melamin köpüğünden de Basotect adı verilen sık gözenekli süngerler üretilebilmektedir. Bu süngerler, $0,033 \mathrm{~W} / \mathrm{mK}$ 1s 1 iletim değerine sahip olduğundan $1 \mathrm{~s} 1$ yalıtım avantajı da sağlamaktadır. 8 ile $11 \mathrm{~kg} / \mathrm{m}^{3}$ yoğunluğu sahip olmanın yanı sıra, kısa zamanlı periyotta $290^{\circ} \mathrm{C}$ 'ye, uzun zamanlı periyotta ise $150^{\circ} \mathrm{C}^{\prime}$ ye kadar yangına dayanıklı olabilen, açı gri renkli, düz yüzey ile piramit yüzeye sahip sünger levha şeklinde de üretilebilmektedir. $1 \mathrm{mx} 2 \mathrm{~m}, 1 \mathrm{mx} 1 \mathrm{~m}$ ebatlarında da üretilebilen ve kendinden yapışkanlı sünger türü olduğundan çeşitli kullanım alanları bulunmaktadır [3].

Yukarıda bahsedilen ses yalıtım süngerlerine, poliüretan maddeden üretilmiş olan çeşitli kimyasal madde içerisinde bekletilerek yanmazlık özelliği de kazandırılabilmektedir. Gözenekli yapıya sahip olduğundan ses yutum değerleri de istenen düzeyde olabilmektedir. Poliüretan ham maddesinden üretilen akustik süngerlerin farklı renk ve desenleri mevcuttur. Yanmaya karşı mukavemetli olan yanmaz süngerlerin, orta ve yüksek frekanslarda bile ses yutum kapasitesinin iyi kapasitede olduğu bilinmektedir. Ayrıca kurşun ve pvc bariyer gibi malzemelerin de eklenmesiyle ses yalıtımındaki performans arttırılabilmektedir. Gürültü içeren tüm ortamlarda akustik açıdan jeneratör, kompresör kabinleri ile havalandırma kanallarında ses absorbe edici olarak kullanılmaktadır. Yoğunlukları ise 50-60 dansite aralığındadır. Yapıştırılabilme özelliğinden dolayı da avantajlar sağlamaktadır [3].

Geri dönüşüm yoluyla, Rebonded Bondex Sünger adı verilen ses absorbe edici süngerler de üretilebilmektedir. İyi düzeyde ses absorbe etmenin yanısıra titreşim sönümleme özelliğine de sahiptirler [3]. Ses absorbsiyoununda etkili olan bir diğer malzeme de Echobone Bondeks'tir. EN ISO Standartlarına göre \% 60- \% 90 aralıklarında ses yalıtımı sağlayabilmektedir. Epdm bariyer ile kullanıldığı zaman, diğer süngerlere göre verimli sonuçlar elde edilebilmektedir. Echobone Bondeks sünger Şekil 12'de verilmiştir [18].
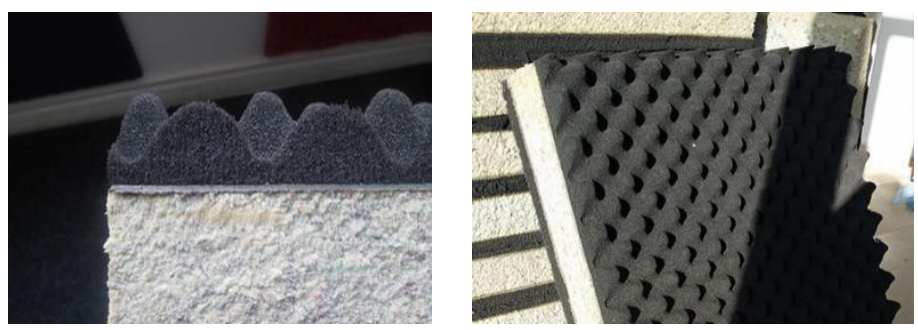

Şekil 12. Echobone Bondeks Sünger [18]

Firexpan sünger tipi de elastomerik kauçuk köpüğü olarak bilinmekte olup, metal, cam, ahşap ve seramik yüzeylerde titreşimden dolayı meydana gelen seslerin engellenmesinde kullanılan, yanmaz özellikte olan kauçuk köpüğü sünger tipidir. Diğer ürünlere göre 4 kat fazla miktarda yalıtım özelliğine sahip olduğu bilinmektedir. Gürültünün kontrol altına alınmasında ve titreșim kaynaklı ses yalıtımlarında etkili olabilecek düzeyde ve yoğunluğu $160-220 \mathrm{~kg} / \mathrm{m} 3$, 1sı iletimi $0,0431 \mathrm{~W} / \mathrm{m} . \mathrm{k}$, çalışma sıcaklı̆̆ $1-40+110^{\circ} \mathrm{C}, 1000 \mathrm{~mm}$ x 2000 mm ebatlarında ve 20mm-50mm kalınlıklarında üretilebilmektedir. Firexpan köpük sünger Şekil 13'de gösterilmiştir [3].

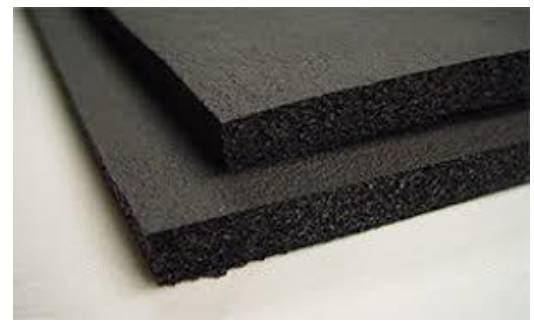

Şekil 13. Firexpan Köpük Sünger [3]. 
Farklı hammaddelerden akustik yüzey elde ederken kullanılan bir lif türü de cam yünüdür. Cam yünü çoğunlukla yalıtım amacıyla tercih edilmektedir. Ses absorbe ederek ve gürültüyü azaltarak sesin yayılımını da engelleyebilmektedir. Ayrıca yanmaz özellikte olması da önemlidir. Düşük frekanslarda ve titreşim gürültülerinde ses absorbe etme imkânı da bulunmaktadır. Çevreye zararsız olması, su geçirmemesi, hafif olması, iyi bir izolasyon sağlaması, tasarım çeşitliliği, alternatif yüzeylere uygulanabilirliği, toksik olmaması ve ses yalıtımını iyileştirmek için odalar arası sökülüp takılabilen paneller içermesi açısından kullanım alanı oldukça geniştir [19].

\section{Sonuçları ve Tartışma}

Fabrikalardaki gürültü seviyesi 80 dB'in üzerine çıkmaktadır. Bu seviye ise kulak tıkacı kullanmayı gerektiren durumlardan biridir. Trafikte bu seviye $90 \mathrm{~dB}$ iken havaalanlarında bu seviye 130-150 dB aralığına kadar çıkabilmektedir [4]. Bu gürültü seviyeleri insan sağlığı açısından risk teşkil etmektedir. İş̧̧i Sağlığ ve İş Güvenliği Yönetmeliğinde, $80 \mathrm{~dB}$ ses düzeyinde 7,5 saat, $90 \mathrm{~dB}$ ses düzeyinde 4 saat kalınabileceği, $100 \mathrm{~dB}$ 'in üzerindeki ses düzeylerinde ise 1 saatten daha az maruz kalınacağ belirtilmektedir [20]. $90 \mathrm{~dB}$ 'in üzerindeki seslere maruz kalındığında, uzun sürede işitme bozuklukları, 130 ile $150 \mathrm{~dB}$ aralığındaki ses seviyesinde ise ani işitme kayıpları ve kulak zarının yırtılması gibi sağlık sorunlarıyla karşılaşılabilmektedir [4]. Bahsedilen sağlık sorunlarını engellemek amacıyla bulunduğu ortama göre farklı şekillerde akustik malzemeler kullanılmaktadır.

Ses absorbe etmede yaygın olarak kullanılan ve en etkili olan malzemelerin akustik süngerler olduğu görülmüştür. Bu süngerlerin, yumurta, piramit, labirent vs gibi farklı şekillerde ve genel olarak 30, 40 ve $50 \mathrm{~mm}$ kalınlıklarında üretilebildiği, ses yutma kapasitelerinin 0,30- 1,12 aralığında olduğu bilinmektedir. Yanmaz özellikte ve uzun sürede $150{ }^{\circ} \mathrm{C}$, kısa sürede ise $290{ }^{\circ} \mathrm{C}$ 'ye kadar 1sıya dayanıklı olabilen türleri de üretilebilmektedir.

Pirinç samanı lifleriyle yapılan çalışmalarda, 20 dB'e kadar, odun tozu ile yapılan çalışmalarda 22 dB'de maksimum ses kaybı sağlanabildiği, dokusuz yüzey kullanıldığında ise hava akış direncinin yüksek olmasından dolayı sesin yalıtımı konusunda önemli aşamalar kaydedilebileceği gibi sonuçlar elde edilmiştir. Yapılan diğer bazı çalışmalarda, birim alana düşen kalınlık ve yoğunluk, kütle, hava geçirgenliği, gerilme mukavemeti gibi fiziksel özelliklerin, akustik özelliği ne yönde etkilediği test edilmeye çalışılmıştır. Testten elde edilen veriler, birim alandaki kütle artışının hava geçirgenliğini azalttığını göstermiştir. Ayrıca ses absorbe etme yeteneğinin minimum frekansta $100 \mathrm{~Hz}$, maksimum frekansta ise $6300 \mathrm{~Hz}$ 'de etkili olduğu belirlenmiştir. Otomotiv sektöründe geri dönüştürülmüş dokusuz yüzeylerin, akustik özelliklerinin iyi olmasının yanında maliyet açısından da avantaj sağladığı sonucuna varılmışır.

Yapılan araştırmalar, düşük yakıtlı hibrit elektrikli araçlarda, sesin emilimi için kullanılacak malzemelerle iletimin etkili bir şekilde azaltılabilmesi için gerekli tasarımların yapılmasının, ekonomik açıdan büyük öneme sahip olduğunu göstermiş̧ir. Örme kumaşların yapısında boşlukların fazla miktarda olması nedeniyle, ses absorbe etmek açısından verimli sonuçlara ulaşılmıştır. Yapılan deneysel çalışmalarda ise gözenekli olan ve olmayan malzemeler karşılaştırıldı̆̆ında, gözenekli yapıların hücresel yapılarından dolayı verimli düzeyde ses absorbe ettiği gösterilmiştir. Ayrıca çeşitli doğal liflerin ses yutma kapasitelerinin araştırıldığı çalışma, akustik frekans değerlerinin 125, 250, 500, 1000, 2000 ve $4000 \mathrm{~Hz}$ olduğunu belirtmiştir. Özellikle de $1000 \mathrm{~Hz}$ ve üzerindeki frekanslarda, titreşimi de engelleyecek şekilde absorbe niteliğinin de sağlandığı gösterilmiştir. Ayrıca doğal liflerin sağlık, çevresel ve ekonomik açıdan da önemli faydaları olduğu ortaya konulmuştur.

Gürülttï önleyici olarak kullanılan akustik malzemeler geliştirilerek deneysel çalışmalar yapılabilir. Farklı yöntemlerle üretilen doğal ve sentetik lif türleriyle elde edilebilecek dokusuz yüzeyler, örme kumaşlar ve süngerimsi yapıların farklı kalınlık ve şekilleri için tasarımlar yapılarak akademik çalışmalar için çeşitli yaklaşımlar ortaya konulabilir. Bahsedilen tasarımların deneysel çalışmalarda kullanılarak özel programlar eşliğinde analizlerinin yapılmasıyla akustik malzemelerle gürültü absorbe etmede etkiyi artırma yönünde literatüre katkı sağlayacaktır.

\section{Kaynakça}

1. Ses ve Gürültü Kontrolü. kisi.deu.edu.tr > userweb > abdullah.secgin/, E.T. 10.01.2020.

2. http://www.muhendislikbilgileri.com/?pnum=134\&pt=G\%C3\%9CR\%C3\%9CLT\%C3\%9C, E.T. 10.01.2020.

3. https://www.sesizolasyonu.net/ses-izolasyonu/gurultu-kontrolu.html, E.T. 10.01.2020.

4. https://www.kenaryazari.com/desibel-nedir-zararli-ses-seviyesi-ne-kadardir/ E.T. 10.01.2020.

5. Toktas, A., Ustun, D., Yigit, E., Sabanci, K., \& Tekbas, M. (2018, September). Optimally Synthesizing Multilayer Radar Absorbing Material (RAM) Using Artificial Bee Colony Algorithm. In 2018 XXIIIrd International Seminar/Workshop on Direct and Inverse Problems of Electromagnetic and Acoustic Wave Theory (DIPED) (pp. 237-241). IEEE.

6. Malawade, U. A., KJ, M., Madhavrao, G. J., \& Virendra, K. B. (2006). Investigation Of Sound Loss Potential Of Natural Fibers and Their Compositions.

7. Zent, A., \& Long, J. T. (2007). Automotive Sound Sbsorbing Material Survey Results (No. 2007-01-2186). SAE Technical Paper.

8. Kalebek, N. A. (2016). Sound Absorbing Polyester Recycled Nonwovens For The Automotive Industry. Fibres \& Textiles in Eastern Europe, (1 (115)), 107-113.

9. Liao, L., Zuo, Y., Meng, H., \& Liao, X. (2018). Research On The Technology Of Noise Reduction In Hybrid Electric Vehicle With Composite Materials. Advances in Mechanical Engineering, 10(3), 1687814018766916.

10. Öztürk, M. K., Nergis, B. U., \& Candan, C. (2010). Akustik Özellikleri Geliştirilmiş Örme Kumaş Tasarımı. Tekstil ve Mühendis, 17(78).

11. Dahil, L., Başpınar, S., \& Karabulut, A. (2011). Gözenekli Malzemelerin Sönümlemeye Etkisi. Afyon Kocatepe Üniversitesi Fen Ve Mühendislik Bilimleri Dergisi, 11(1), 1-7. 
12. Kaya, A. İ., \& Dalgar, T. (2017). Ses Yalıtımı Açısından Doğal Liflerin Akustik Özellikleri. Mehmet Akif Ersoy Üniversitesi Fen Bilimleri Enstitüsü Dergisi, 8(Özel (Special) 1), 25-37.

13. https://www.izoder.org.tr/dosyalar/egitim-faaliyetleri/ytu-ses-sunumu-ayhan-cakir.pdf, E.T. 12.01.2020.

14. http://haliccevre.com/images/PDF/s-17.pdf, E.T. 12.01.2020.

15. http://www.sesyalitimsungeri.com.tr/akustik-kumas.html, E.T. 12.01.2020.

16. https://www.akustikkaplama.net/paneller/akustik-kumas.html, E.T. 13.01.2020.

17. https://www.teknikakustik.net/renkli-piramit-sunger.html, E.T. 13.01.2020.

18. https://www.yanmazsunger.com.tr/sesyalitimsungerleri/echobone-bondex-sunger-kirpinti-bondeks-ses-yalitim-sungeri.html, E.T. 13.01.2020.

19. https://www.vegaakustik.com/cam-yunu-akustik-panel/, E.T. 13.01.2020.

20. Ece, F., Sümer, S. K., \& Sabanc1, A. (2003). Tekstil Fabrikalarında Gürültü Düzeyi ve Etkileri. TTB Mesleki Sağllk ve Güvenlik Dergisi, 4(15), 30-39. 